\title{
Research on Several Problems in the Implementation of College Physical Education Curriculum
}

\author{
Limin Peng \\ Traditional Chinese Medicine College of Yunnan 650200, China
}

Keywords: colleges and universities; physical education curriculum; problems; countermeasures

\begin{abstract}
As an integral part of school sports in China, college sports is one of the important ways to realize the overall goal of school sports in China. However, in practice, although various forms of trials and studies have been conducted in this field in recent years, the effectiveness is not obvious. This article discusses from the aspects of the guiding ideology of physical education teaching, teaching content evaluation, and other aspects, proposes corresponding countermeasures and suggestions by analyzing the existing problems, and strives to make the implementation and development of physical education curriculum more in line with the needs of reform.
\end{abstract}

\section{Introduction}

Physical education in colleges and universities is the last link in the life cycle of lifelong physical education, and it is also the key to realize the idea of lifelong physical education. It is incumbent upon students to do well in physical education and health education and enable students to truly realize the curriculum in physical education teaching obligation. The author intends to proceed from the contents, teaching methods and evaluation criteria of the development stage of physical education curriculum in colleges and universities, and to systematically analyze the problems existing in the implementation of higher vocational college physical education curriculum in order to change the current existence problems of higher vocational college physical education curriculum. It provides reference for the construction and development of higher vocational college sports curriculum system.

\section{Problems in the implementation of college sports curriculum}

\subsection{The education concept is backward}

Since the 1980s, foreign countries have actively advocated new sports education concepts such as "happy sports", “career sports", "health sports”, and "lifelong sports". In the late 1990s, China also proposed a series of reforms that corresponded to it. However, in the minds of many physical education teachers today, the teaching concept of competitive sports is deeply rooted, and the concept of physical education has not changed so much that the entire concept of physical education cannot adapt to the students' health needs.

\subsection{Outdated teaching content}

Teaching content is an important part of the curriculum and an important part of achieving the course objectives. However, when the new curriculum concepts and curriculum standards have undergone essential changes, the content in college sports teaching has not changed much. Resulting in effective convergence of curriculum concepts and teaching.

\subsubsection{The choice of teaching content is too inflexible and lacks features}

In the new round of curriculum reform, the content of the curriculum is required to be more selective. Although some specific contents are listed in the "New Curriculum Standards", it is only as a local content recommendation when implementing physical education. The specific initiative is entirely in the hands of local education units and physical education teachers. However, at present colleges and universities in physical education teaching because the school or some of the physical 
education teachers did not correctly understand the real connotation of the new period of physical education curriculum reform, still copy all the contents of the traditional physical education teaching, trying to be comprehensive in teaching content. In fact, what the country need is through the teaching of physical education curriculum. It will eventually stimulate all students' interest in sports and form a habit of adhering to physical exercise, so that in the future energetic work and life will make greater contributions to the country and society. This requires each school teacher to choose their own distinctive teaching content according to the students' interests in different regions and cultural areas to meet the students' needs for sports.

\subsubsection{Teaching Content Competition}

Before the 1980s, our country's school sports had been developing along with the idea of training reserve talents for competitive sports. In the late 1980s, China's education department re-examined the function of school sports and established the "health first" important physical education concept. It provides an important theoretical basis for the formulation of school physical education curriculum standards at all levels and that is school sports should not and cannot make substantial contributions to competition. What they achieve is two distinct goals that should be treated differently. In terms of content selection, school sports cannot be constrained by competitive sports. All sports that students have interests in and those do beneficial to students' physical and mental health should become schools' teaching content. However, so far, in the physical education of colleges and universities, under the influence of traditional thinking, some competition n events in the competitive arena have been used. such as:

The pace of development, strength, velocity and endurance are that teachers usually use sprinting, throwing, middle-distance running, or long-distance running teaching. Ignoring high-quality ball games and kinds of games which can also achieve the above-mentioned qualities.

\subsection{Teaching methods are too traditional}

\subsubsection{Instilling pedagogical methods and exam-oriented education are still in domination in schools.}

Physical education classes are highly practical courses that focus on action. College physical education classes only once a week for 90 minutes, should allow students to fully, freely, and happily in this limited time. In the traditional teaching process, teachers are generally used to explain, demonstrate while students imitate and practice, and successively repeat the mistakes to the right teaching process. In this fixed teaching form, explanations and demonstrations mainly rely on teachers, and the student's dominant status is not enough. In addition, the purpose of teaching is still trapped in the "Test-for-sports" teaching model. Physical education courses are designed for examinations, teachers teach for examinations, and students learn for examinations. Students are always in a passive learning process, leaving students with no learning or thinking space, which restricts the development of students' personalities, cannot truly realize the purpose of the curriculum that is based on students' "health first" or student-orientation, and ultimately affects the realization of the overall goals of the curriculum.

\subsubsection{Systematic Teaching Method Fails to Break the Teaching Tradition of School Sports Competition}

Systematic pedagogy places great emphasis on the systematic nature of students' technical movements. In fact, this teaching method completely transfers the training methods of athletic sports to physical education classroom teaching. For example, when teaching a basketball dribbling, some teachers always start dribbling from the ground, then teach dribbles between marches, and then change to dribbling, emergency stop dribbling, etc. For sports teaching for all students. Whether we have to teach systematically, what is the effect of such a systematic teaching? Because there is only one 90-minute physical education class a week, students can only learn a little bit of water. In addition, this teaching method does not meet the physical and mental development characteristics of ordinary students. The systematical teaching method created by modern sports 
civilization is to allow athletes to compete in arena, instead of allow our students to learn to live and survive. That being the case, the physical education classroom teaches the students such skills systematically. Moreover, the main purpose of physical education teaching is not to train all students as athletes.

\subsection{Evaluation Content and Means Simplification}

\subsubsection{Single Evaluation Content}

In addition to require students to master basic knowledge and skills, the current physical education curriculum objectives in China also require students to develop physical habits, develop adaptations, will qualities, bravery, tenacity, and aggressive spirit in the external environment, completely changing the original content of the evaluation, but for the current physical education teachers in colleges and universities, they still can not accurately grasp the five areas required by the new curriculum goals, in the course of the implementation of the curriculum is still used to evaluate relatively simple motor skills and physical fitness, can not Really realize the goal requirements of physical education curriculum in the new period.

\subsubsection{Evaluation Tools and Methods Monotonously}

Evaluation is an important part of the implementation of physical education curriculum, and it has a direct connection with the goals of physical education curriculum. Whether the method is proper or not also influence the direct realization of the achievement of the objectives of the curriculum. However, due to the impact of traditional physical education curriculum evaluation methods and the environment of exam-oriented education, a considerable proportion of physical education teachers in the implementation of physical education curriculum are relatively monotonous and poor in evaluation of student learning, both evaluation methods and evaluation tools. The traditional evaluation methods such as teacher evaluation and terminator evaluation are still used, and the evaluation tools are paper examinations and physical fitness skill tests. The difference characteristic and other disciplines between competitive sports and school sports have not been mastered, so that students cannot fully develop and effectively arouse their interest in sports learning.

\section{Some suggestions for the development of college sports curriculum}

\subsection{Improve teachers' professional knowledge and strengthen the construction of teachers}

\subsubsection{Strengthen In-service Training for On-job Teachers}

At present, a considerable number of college teachers who received an out-dated high education even some have not received a professional high education are still play a key role in today's education area. Their thoughts are deeply influenced by the traditional education model. Know little about the renewal of knowledge and the content of reforms in the current curriculum of physical education and health. In addition, for some young teachers in the professional study is also in the experimental period of our country's physical education curriculum reform, some concepts of the new curriculum can not be accurately grasped, so that in the implementation of physical education curriculum they were more confused. Therefore, schools should use the methods of sending professional teachers to professional colleges for professional training, set up class competitions in schools, inviting experts for guidance, inviting experts to give special lectures, and organizing seminars to improve and update teachers' knowledge structure. In order to improve their own teaching ability.

\subsubsection{Do a good job of checking the skills and knowledge level of newly recruited teachers}

Since the end of the last century, higher education has begun to expand enrollment. As a result, in a period of time, the proportion of teachers and students has become uncoordinated in many colleges and universities. The introduction of teachers has become extremely important for each type of school in the following years. work. For the introduction of new teachers, first of all schools 
should develop specific academic requirements, to avoid some non-standard methods in the process of operation. In addition, in the investigation of the new teacher's professional abilities, it is necessary to take into the particularity of physical education into account. Not only should the technical skills with strong practical ability should be strict inspect, but also the knowledge of the promotion of body-relevant theoretical knowledge should be pursued. The introduction of theory and practice are more comprehensive dual-line outstanding talents.

\subsection{Strengthening the setting and innovation of teaching content}

\subsubsection{Setting Course Contents Based on Interests and Needs}

At the university level, with the maturity of the students' physiology and psychology, a comprehensive and effective sports values gradually formed among students, with broad interests and practical results. According to this feature of the students, the combination of university sports programs and class hours cannot be simplified, but in-depth, thorough analysis and research are needed to provide a variety of programs which are suitable for the characteristics of students to satisfy students' various sports special needs. While strictly following the syllabus, universities and colleges can make flexible and effective arrangements for the allocation of sports items according to their actual and professional needs. For most students, some fitness sports, such as aerobics, yoga, and martial arts, are all their favorite items that they could not have achieved in the middle school era. Furthermore, with the progress of society and the improvement of people's living standards, many sports events have entered social occasions, such as ballroom dancing, gateball, tennis, bowling, and golf, which are all common sports events in social situations. The above-mentioned students of these projects not only have higher interest but also benefit their future in society.

\subsubsection{Combining general education with electives to give full play to student autonomy}

In summary, the author thinks that the arrangements of the content of college physical education should exclude the setting of certain specific content, and schools should give full play to students' autonomy and respect students' choices, so as to mobilize their enthusiasm. However, student self-selection is not an arbitrary choice. It should be combined with the syllabus to combine the general and elective courses on the course content, and the course selection mode in which the students choose the courses within a certain range of elective and arbitrary elective courses. To be specific, a certain range of choices are taken for general education courses. That is, to set certain specific items, students do not need to be fully renovated but must complete a certain number of items. But what is special is that the theory of physical education courses must be studied by every student. This may be about one or two sessions per semester. Students can choose specific study projects independently and they can also choose the elective courses arbitrarily. According to the syllabus and students' interests and needs, the general courses can be set to Taijiquan, basketball, volleyball, etc.; elective courses can be set in many sports, it is difficult to reach every aspect of a matter, the institutions can be based on specific and current conditions, students interests, hobbies, and the availability of teachers.

\subsubsection{Arrange classes according to the stage of the situation}

Through comparative analysis, the author believes that the specific course arrangement can be carried out as follows: 1 . In the first year of university, students should chosen a general course for each semester, and the rest is arbitrarily chosen; 21 syllabus of physical education courses is set for each semester. Each student is required to be trained. The content is health care, self-exercise method, sports physiology and anatomy knowledge, rules of the game, refereeing law, organization of activities, and sports games. 3. More than 3 various types of sports competitions should be organized to arrange students to participate in organizations, referees, and other work in order to exercise their practical capabilities. Through the competition to promote the mastery of sports knowledge and improve their conscious participation in physical exercise interest. 


\subsection{Establish sports curriculum goals}

The goal of the physical education curriculum is to elaborate the overall goals and stage goals of the course in terms of the country's education policy and the requirements of quality education, from the aspects of sports knowledge and skills, processes and methods, emotional attitudes and values. It is the basis for teaching evaluation and teaching management. Taking into account the differences in the level of physical development of students, curriculum objectives are divided into basic goals and development goals. The basic goals are established according to the basic requirements of most students. The development goals are established for a small number of students who have a strong command of knowledge and skills, and they can also serve as the goal of most students. As our country's physical education curriculum is still in an excessive period from the traditional model to the new curriculum model, teachers have a higher degree of recognition of traditional standards and clear curriculum. Therefore, each school should concretely, accurately, and scientifically describe the objectives of the course in the areas of athletic participation, sports skills, physical foundation, mental health, sports culture, social adaptation and other fields. Level. In order to find out the direction for teachers to use specific methods and methods in practice.

\subsection{Optimizing the Evaluation of Physical Education Curriculum}

The evaluation of traditional physical education curriculum is based on a single teacher evaluation and a curriculum model that evaluates simple content such as sports skills. This obviously no longer meets the basic needs of curriculum development in the new era. According to the reform concept of the new curriculum, the author believes that the evaluation of sports curriculum should include three aspects that are conducive to the promotion of student learning, teacher teaching and curriculum construction. The student's learning evaluation should be the evaluation of the learning effect and the process, and it is also the evaluation centered on the degree of achievement of the goal, and it should be conducted through self-assessment, peer assessment and teacher commentary. In the evaluation, the pros and cons should be diluted, the functions should be selected, the rewards should be strengthened, and the functions should be developed. The progress of the students should be included in this evaluation. To strengthen the evaluation of diagnosis and improve the function, we must find problems and solve problems through evaluation.

\section{References}

[1] Yaju Li. Research on the Innovation of Current College Physical Education Curriculum Reform[J]. Journal of Anhui Normal University: Natural Science Edition, 2008, (5).

[2] Muju Zhu. Into the new curriculum [M]. Beijing: Beijing Normal University Press, 2002.

[3] Xiaojun Huang, Zuo Xinrong. Present Situation and Countermeasures of Track and Field Course Electives in Colleges and Universities of Anhui Province[J]. Journal of Anhui Normal University: Natural Science Edition, 2008, (3).

[4] Huijun Ling, Qian Jie. Research on modern college sports curriculum[J]. Journal of Anhui Normal University: Natural Science Edition, 2006, (4).

[5] Yongming Chen. Modern Teacher Theory [M]. Shanghai: Shanghai Education Press, 1999.

[6] Huilin Wang. College Physical Education Teachers' Quality Reconstruction from Sports Curriculum Reform in Colleges and Universities [J]. Journal of Gansu Lianhe University, 2005(1).

[7] Taiqi Guo, Shaowei Pan. Implementation of New Curriculum Standards and Repositioning of Physical Education Teachers' Roles[J]. Journal of Physical Education, 2004, (9). 